\title{
Using Portfolio Theory to Improve Resource Efficiency of Invested Capital
}

\author{
Steven Byers, John Groth and Tomohiko Sakao
}

\section{Linköping University Post Print}

N.B.: When citing this work, cite the original article.

Original Publication:

Steven Byers, John Groth and Tomohiko Sakao, Using Portfolio Theory to Improve Resource Efficiency of Invested Capital, 2012, Conference of the Greening of Industry Network.

Postprint available at: Linköping University Electronic Press http://urn.kb.se/resolve?urn=urn:nbn:se:liu:diva-84858 


\title{
Using Portfolio Theory to Improve Resource Efficiency of Invested Capital
}

\author{
Steven S. Byers ${ }^{1}$ \\ Professor of Finance, College of Business, Idaho State University, USA \\ John C. Groth ${ }^{2}$ \\ Professor of Finance, Texas A \& M University, USA \\ Tomohiko Sakao ${ }^{3, *}$ \\ Professor, Dept. of Management and Engineering, Linköping University, Sweden \\ * Corresponding author
}

\begin{abstract}
The diligent use of capital of all forms contributes to sustainability. In fact, capital employment is a common factor in sustainability research and in the practice of sustainability management. For example, capital usage is included in research in environmental sustainability in the context of sustainable consumption. Product/Service Systems (PSS), which includes product sharing as one concrete form, has been addressed in research on that context. However, virtually no literature provides concrete, theory-based methods for quantifying the effects of sharing products. The goal of this paper is to describe the potential contribution of portfolio theory in order to quantify the effects and optimize the employment of capital in a theoretical and quantitative manner in the context of sustainability. Practices tied to the prescriptions of portfolio theory can contribute to environmental sustainability. The core perspective can be summarized as follows: the pooled, portfolio approach to asset management yields a reduction in assets employed and used relative to the volume of demanded resources used for need fulfillment.

To reach this goal, the paper first provides a brief literature review from the "finance side" of literature. Then, the "engineering side" literature offers a few examples of others who have applied the prescriptions of portfolio theory to "engineering" application.

After that, it provides an overview of the core issues and implications of portfolio theory, and develops some ideas to support application of portfolio theory. The provided insights illustrate how portfolio principles applied outside the arena of investments can yield benefits, including the fulfillment of needs with the least resource used - a core principle in sustainability. In particular, the "pooling" of assets/services to meet uncertain demands from different users of an asset/service pool may yield benefit from diversification effects.

Furthermore, the paper offers additional avenues for future research. It describes how this special application of portfolio theory outside the realm of finance can yield benefits that positively affect the creation of value and resource use in an economy at large.
\end{abstract}

Key Words: Sustainable consumption, resource use, efficiency, need fulfillment ratio, servicizing, value creation

\footnotetext{
${ }^{1}$ byerstev@isu.edu

${ }^{2}$ MindCapitalOne@yahoo.com

${ }^{3}$ Post: Dept. of Management and Engineering, Linköping University, SE-581 83 Linköping, Sweden.

Tel: +46 13 282287. Email: tomohiko.sakao@liu.se
} 


\section{Introduction}

The diligent use of capital of all forms contributes to sustainability. ${ }^{1}$ In this paper, we refer to changes in the use of capital to fulfill human needs as an instance of a phenomenon sometimes called servicizing (White et al. 1999), a potential measure to realize sustainable consumption. As an illustration of how the use of physical product (capital) has changed, consider the increasing popularity of car sharing by companies such as Zipcar. Separate from employment of capital issues, this example illustrates the impact on the relation between the provider of the capital (car) and the user of product. Specifically, elements of control of the product shifted from the user to the provider.

In the servicizing context, providers' views of products might differ considerably from individual purchase choices. The car example illustrates other ramifications of servicizing, e.g., users, redeployment of capital, purchase price of the asset, risk management, asset maintenance, returns on capital sensitive to asset use versus idle time. These factors related to the diligent use of capital to fulfill needs also impact sustainability. Important questions for a provider in this situation include how to manage economic profits and risks of employed capital. Economic profits and value added are sensitive to economic returns and the employment of capital over time. Reducing idle time - since idle capital results in negative rather than no returns - not only enhances returns, but increases returns relative to capital employed.

Unemployed or inefficiently employed assets diminish need fulfillment relative to resource use. Hence, enhancing resource use relative to capacity and avoiding idle time favorably alter the need fulfillment to resource use ratio (NF/RU). Need fulfillment is taken into account as functional unit in LCA (Life Cycle Assessment). However, NF is used in this paper to refer to something more fundamental. This ratio is explained in detail shortly.

Practices tied to the prescriptions of portfolio theory can contribute to environmental sustainability. The core perspective can be summarized as follows: the pooled, portfolio approach to asset management yields a reduction in assets employed and used relative to the volume of demanded resources used for need fulfillment.

Resources include financial resources, tangible resources, and human resources. Optimal resource employment includes the effective use of human resources. Pooled assets offer the prospects of more efficient use of human resources as well as financial and tangible assets. Wise use of resources favorably influences the employment of human talents with attendant effects on social sustainability. In fact, the effective use of human resources is more important than the use of other resources - since a human resource is an expiring resource. At the end of each day, the day is forever gone for a person. In contrast, unused financial or tangible assets have potential future uses, and returns.

The efficient use of resources to fulfill human needs with the resultant earning of economic returns supports employment opportunities. In contrast, the inefficient use of resources has economic costs that fall on society - and rob its members of need fulfillment and the beneficial use of human resources.

Few studies have investigated effects of the efficient use of resources in the context of portfolio theory and sustainability. For instance, Tukker has argued, in a semi-quantitative manner, the possibility to reduce environmental impacts by up to factor 2 through this type of asset pool offering (Tukker 2004) to meet demand and need fulfillment. On the other hand, some quantitative studies are reported about quantitative effects as regards to particular cases (e.g. (Sundin et al. 2010)). Virtually no literature provides theoretical formulation of quantifying the effects. 
The motivation for this paper stems from the recognition that the principles of portfolio theory offer the prospect of favorably affecting value creation in areas away from the arena of financial investments. This notion is not unique to our efforts. However, this paper differs from previous important contributions in that it focuses on specific benefits of portfolio concepts that:

- Are beneficial to the use of capital in need fulfillment, with favorable effects on sustainability.

- Offer the promise of garnering incremental as well as separate potential benefits from servicizing.

- Yield benefits when applied to other activities related to the inputs of production, production itself, delivery, and realization of need fulfillment by people.

- Increase efficiency in the employment of capital, with attendant benefits to organizations, economies, and society consistent with the prescriptions of sustainability. $^{2}$

This paper is not a case study, nor does it introduce a new quantitative model. The model we reference is already quite well-known and very quantitative. It has been applied to every conceivable area of finance, and has been acknowledged with the several Nobel Prizes in the area of economics. Rather, this paper takes the intuition and logical outcomes of these modern portfolio models and applies them in the area of sustainability management. The goal of this paper is describing the potential contribution by portfolio theory in a theoretical and quantitative manner in the context of sustainability and presenting areas of future research. To do so, Section 2 provides a brief literature review from the "finance side" of literature, the review limited to seminal papers that support the background section. Next, a brief review from the "engineering side" literature offers a few examples of others who have applied the prescriptions of portfolio theory to "engineering" application. Section 3 provides an overview of the core issues and implications of portfolio theory, while Section 4 develops some ideas to support application of portfolio theory. Section 5 relates principles of portfolio theory to invested capital. In addition, Section 5 provides additional avenues of research, before making conclusions in Section 6.

Favorably influencing the inputs of production, production, delivery, and realization of need fulfillment by people is central to sustainability. Adding to the efficiency in the employment of capital, with attendant benefits to organizations, economies, and society consistent likewise are crucial to the prescriptions for sustainability.

Before proceeding, we offer a brief description of the Need Fulfillment/Resource Use Ratio. People and other consumers (e.g., cattle at a feedlot) have actual and perceived needs and desires that are for simplicity termed needs. These entities utilize (or contribute to) resources (human, tangible, and financial) to fulfill needs.

$$
N F R U=\frac{\text { Need/Desire Fulfillment }}{\text { Resources Employed/Used }}
$$

A high need fulfillment to resource ratio implies efficiency in the use of resources. This does not imply a wise use of resources as viewed by individuals or "society." Wise use is a separate and important issue sensitive to many issues including cultures, attitudes, and priorities. The authors defer discussion of the details of these issues, e.g., the impact of waste on efficiency, sustainability, costs, etc. to other papers, rather than detract from the focus of this paper. 


\section{The Literature}

\subsection{Finance}

Modern portfolio theory originates in the 1950s with the seminal work of Markowitz (Markowitz 1952). Markowitz developed the formulation of an efficient frontier from which an investor could choose their portfolio to maximize return for a given level of risk as measured by the variance of returns. A key insight from this work was that assets could not be selected based solely on their unique characteristics of return and variance. Rather, an investor had to consider the correlation of the returns of an asset with the returns of all other assets. Taking into account these co-movements allowed the construction of a portfolio that had the same return with lower risk than a portfolio that ignored the interactions (Elton et al. 1997).

(Sharpe 1964) and others (Lintner 1965) and (Mossin 1966) recognized and advanced some of the potential implications of portfolio theory. Building on the work of Markowitz, Sharpe developed the capital asset pricing model (CAPM). The CAPM quantifies an investor's required expected rate of return on an asset given the asset's sensitivity to systematic (market) risk. Other researchers tested the CAPM and developed various versions of the model over the years, most notably (Fama et al. 1992). Many more researchers developed and offered important variations, tests, and applications of the basic models. All of these efforts have rested on the bedrock of the early explorers. The references in this paper offer a minute sampling of the many significant contributions.

The results of the research into portfolio theory have affected the management of money and other assets worldwide. The genius of these ideas and the intellectual leverage brought by many of the greatest minds in finance bridged the gap from mathematics to reality, resulting in trillions of dollars of assets invested and managed according to the prescriptions of modern portfolio theory. The Nobel Committee recognized these tremendous achievements and contributions conferring both Harry Markowitz and William Sharpe with the 1990 Nobel Prize in Economics.

\subsection{Sustainability and Servicizing}

Environmental sustainability has been an issue in recent decades in design (e.g. (UNEP 1997)), production (e.g. (Ron 1998)), and supply chain issues (e.g. (Bai et al. 2010)). Additionally, one of the concepts underlying different environmental corporate activities is extended producer responsibility (EPR) (OECD 2001). EPR contributes to producers' broadening the area of their concern to issues such as product lifecycle. Researchers and practitioners have developed different concepts to express efficiency of resource usage in a product lifecycle. MIPS (Material Input per Service Unit) (Weizäcker et al. 1998) is among the most known concepts. Eco-efficiency (DeSimone et al. 1997) finds more general application in calculating such efficiency, although it is yet to be standardized in terms of calculation methods (Huppes et al. 2005).

On the other hand, some literature illuminates a trend sometimes called servicizing (White et al. 1999) and a shift from focus on a product to a focus on service. One reason for shifts in the nature of the demand side rests in the "servification" of consumers' behaviors, meaning a shift from customers' consumption of physical products to consumption of softer or solution-based services (Sakao et al. 2007). In more detail, many customers prefer to avoid owning non-core physical products for their business (Sakao et al. 2009a). Reasons for this preference include avoiding assets on the balance sheet for a variety of reasons. For example, lower total capital increases the profit/total capital ratio, an important key performance index. 
In addition, customer needs change. Ownership reduces flexibility to change (depending on the form of leasing contract, which may be expensive to break in advance).

In the supply side parallel to the trend above, a concept known as Total Care Products (Functional Products) (Alonso-Rasgado et al. 2004) - which comprises combinations of hardware and support services - has been developed in the domain of engineering design. This is similar to the concept known in the literature as Product/Service Systems (PSS) (Tukker et al. 2006b). These combination-oriented concepts are relatively new compared to those concepts addressing pure services; e.g. new service development (Edvardsson 1997) and service engineering (Bullinger et al. 2003).

PSS essentially consists of "tangible products and intangible services designed and combined so that they jointly are capable of fulfilling specific customer needs" (Tukker et al. 2006a). PSS often include analysis in the context of environmental sustainability. For instance, Tukker has shown the possibility of reducing environmental impact by a factor of 2 , (i.e. reduction by 50\%) as a result of product categories pooling out of eight types of PSS (Tukker 2004). However, this calculation rests on a conceptual model. Virtually no literature provides concrete, theory-based methods for quantifying the effects.

Environmental sustainability and servicizing are two important factors leading product providers towards more effective capital management. As a result, service activities such as maintenance, customer support, and product take-back enjoy increased incorporation into the design space (Sakao et al. 2009b). Traditionally, physical products in manufacturing industries have dominated this area.

Scrutiny of the "sustainability and servicizing side" literature yielded few examples of others who have applied the prescriptions of portfolio theory to "sustainability" application. Krysiak's valuable contribution evaluated consequences of actions (or projects) in the context of sustainability and characterized the trade-off between sustainability and efficiency (Krysiak 2009). He provided an interesting choice rule for a special case that has a connection to portfolio theory. However, little literature applied portfolio theory to these challenges.

After a reasonable search, we conclude this paper represents one of the first attempts to apply portfolio theory, concepts, and mathematical models to managing (in the servicizing context) a pool of physical products or available service units as a portfolio of invested capital. This approach allows quantification of decisions important in the different aspects of invested capital.

\subsection{Industrial cases}

Different examples of practices to provide pooled asset capital in both B2C and B2B are reported. A well documented B2B case comes from Toyota Material Handling Group (TMHG) which is based partly in Sweden. TMHG is one of the world's leading forklift truck producers and offers trouble-free material handling operations worldwide through a complete range of products and services rental programs using their pooled asset (Lindahl et al. 2009, Sakao et al. 2009a). Examples of different offers within a rental solution are:

- rapid response to ensure that the customer's operations keep running;

- guaranteed performance levels with a money-back commitment;

- total support from the company's service organization with rapid and guaranteed response times;

- ability to change or upgrade equipment without additional cost, subject to 3 months' notice; 
- ability to return equipment if it is no longer required without additional cost, subject to 3 months' notice; and

- Option of including a truck driver as part of the rental agreement.

Examples of benefits are that they provide a flexible solution that one can adjust depending on the customer capacity needs. These solutions help the customer to avoid the uncertainty of forklift truck running costs, as well as eliminating the need to tie up capital (thus, risks of ownership), which might have better opportunities and returns if employed in other areas of the customer's business. Actually, TMHG is not interested any more in selling a higher number of forklifts. Rather, they seek to maximize economic returns while selling fewer forklifts. Obviously, in pooling asset capital, it is critical for the economy of the business to decide an appropriate number of products to be managed.

An example from B2C is the car sharing example above. Potential environmental benefits of this include reduction of resource consumption attributable to shared usage of vehicles as well as decrease of mileage per person. For the latter, (Prettenthaler et al. 1999) reports that a move from car-ownership to car-sharing is found to trigger significant reduction of mileage of private vehicles; i.e. reduction of between $42 \%$ and $50 \%$. Note that the environmental impact of a car is dominant from its usage phase in general, and thus it is reasonable to have primary interests in the mileage from the environmental viewpoint. In addition, keys for success in the car sharing concept at Daimler-Benz have been identified; e.g. convenience for users who already own one and cost advantage for those who don't at the moment (Johnson et al. 1998).

Little literature addresses quantification of decreased assets in practices of car sharing. From a business perspective, it is of interest that Honda ICVS (Intelligent Community Vehicle System) discontinued their car-sharing service in Singapore in 2008 after 6 years of operation. They state "the decision to discontinue the program was reached as it was assessed that it would be difficult to sustain the service with the current operation system." 3 See (Yamaguchi 1999) for general information of Honda ICVS. Theoretical insights in quantitative terms about pooling asset capital could help support the planning of this type of business and could cast light on the difficulties encountered in the Honda example.

\section{Background Theories}

\subsection{Overview}

Portfolio theory (PFT) rests on a number of assumptions. One, for example, relates to what economists call perfect capital markets. The decisive works include (Markowitz 1952) and (Markowitz 1959). (Elton et al. 1977) provide a very digestible perspective on key issues. (Goetzmann 2010) provides an outstanding and far more complete summary of PFT issues than we do in this paper. Rather than burden the reader and given our objectives, we move to the fundamental ideas and connections, first with respect to statistics, then in terms of financial assets, and finally, in the context of our application.

\subsection{Statistics}

Thinking in terms of two variables is adequate for us to grasp the concepts. Combing two random variables $(\mathrm{x}, \mathrm{y})$ having expected values and corresponding variance $\left(\sigma_{x}^{2}, \sigma_{y}^{2}\right)$ in expected values results in a simple weighted expected value. One chooses the weights $\left(\mathrm{w}_{\mathrm{x}}\right.$, $\mathrm{w}_{\mathrm{y}}$ ) for each variable, these weights representing the fraction of each dollar in the particular asset. The weights total 1.0. With just two variables, the weight not in $\boldsymbol{x}$ must be in $\boldsymbol{y}$. Hence, if one chooses $\mathrm{w}_{\mathrm{x}}$, then $\mathrm{w}_{\mathrm{y}}=\left(1-\mathrm{w}_{\mathrm{x}}\right)$. The expected value for the portfolio is, 
(1) Expected Value $E\left(r_{p}\right)=w_{x} E\left(r_{x}\right)+w_{y} E\left(r_{y}\right)$

Allow the expected values of the variables to have a particular correlation, $\rho_{\mathrm{x}, \mathrm{y}}$. As usual, the correlation coefficient $\rho$ might range from +1 to -1 . The expected variance for combining variables is:

(2) $\sigma_{p}^{2}=\sum_{x=1}^{n} \sum_{y=1}^{n} w_{x} w_{y} \operatorname{Cov}\left(r_{x} r_{y}\right)$

Where $\operatorname{Cov}\left(r_{x}, r_{y}\right)$ represents the covariance of expected returns of $\mathrm{x}, \mathrm{y}$.

With two variables, (2) simplifies to

(3) $\sigma_{p}^{2}=w_{x}^{2} \sigma_{x}^{2}+w_{y}^{2} \sigma_{y}^{2}+2 w_{x} w_{y} \operatorname{Cov}\left(r_{x}, r_{y}\right)$

Because covariance and correlation enjoy this relationship:

(4) $\operatorname{Cov}\left(r_{x}, r_{y}\right)=\rho_{x y} \sigma_{x} \sigma_{y}$

We can rewrite (3) as:

(5) $\sigma_{p}^{2}=w_{x}^{2} \sigma_{x}^{2}+w_{y}^{2} \sigma_{y}^{2}+2 w_{x} w_{y} \sigma_{x} \sigma_{y} \rho_{x y}$

Given any choice of weights $\left(\mathrm{w}_{\mathrm{x}}, \mathrm{w}_{\mathrm{y}}\right)$, the maximum variance for (3) occurs when all the values are positive and maximized. The combinations of the squared terms and the fact that the weights are positive makes the first two terms positive. Thus (3) has positive maximum value if $\rho_{x, y}$ is +1.0 .

\subsection{Finance}

Professor Markowitz made the association to application by thinking of the effects in terms of financial and other assets. For example, one might think of a prospective investment opportunity and characterize the potential outcome in terms of its expected return and the variance of the expected return for a time period, e.g., daily or monthly.

Second, sensing what presumably many had overlooked, he recognized that the expected returns of assets for a given period are likely always something less than perfectly positively correlated. If the correlation coefficient is less than +1.0 , then the variance of the combined variables must be less than the maximum in (3). The core conclusion: combine assets having less than perfectly correlated returns and

- The expected return is a simply weighted sum of the individual expected returns.

- The variance of the return of the portfolio is less than the maximum.

Having nothing magical occurs in terms of expected returns of a portfolio, but reducing the expected risk of its returns offers benefit. The risk eliminated or "diversified" away gained the label of unsystematic risk (U-risk) or asset (e.g., stock) specific risk. Any undiversified Urisk plus "systematic" risk (S-risk) represented the expected risk that remained in a portfolio following diversification efforts. The elegance of Markowitz's developments included the 
Min-Max criteria: minimize expected risk given an expected return; maximize expected return given a level of risk.

Complete or "perfect" diversification implied the elimination of all U-risk, with only Srisk left. Conceptually, that perfectly diversified portfolio at a moment in time represented ownership or the correct weights of all assets of risk that exist at that moment - characterized by some as the "market portfolio."

With more than two investments, one can portray the correlation/covariance relationships in a matrix. Rather than address this in detail, the Appendix offers a sample of this.

Many other developments as well as the normal degree of arguments and questions have resulted in numerous contributions to the literature. One finding is of special relevance for this paper. (Statman 1987), building upon on the prior work of Evans (Evans et al. 1968)and Elton (Elton et al. 1977) shows that the risk of a portfolio falls precipitously as new securities are added to the portfolio but quickly levels off after the addition of only around 20-30 securities. The securities added are chosen randomly. These findings illustrate that the elimination of unsystematic risk occurs fairly rapidly, and requires only naïve diversification. We know that the risk of a portfolio depends on the proportions of the individual stocks along with their variances and covariances. If the securities were to be chosen carefully with respect to those characteristics, it is possible to eliminate unsystematic risk even more quickly. Those studies suggest that selecting the right securities to combine in a portfolio - results in a rapid diversification effect using a relatively small number of securities. Figure 1 illustrates this effect without great detail.

$<<$ Position of Fig. 1. $>>$

Fig. 1. Diversification of unsystematic risk with increase in number, $\mathrm{n}$.

\section{Application - Non-Financial Assets}

\subsection{Portfolio Theory, Capital, and Demand Fulfillment}

PFT generally proceeds in terms of financial assets characterized with two specific parameters, the expected return on an asset, and the standard deviation of that expected return. Since our interest resides in finding incremental benefits from servicizing, we take an alternate approach.

First, with the results of studies of the risk of portfolios of securities depicted in Figure 1 fresh in mind, we share some implications. The fact that relatively few random variables yield potential great benefit in risk reduction holds our attention: comparatively few participants in an asset use "pool" offer the prospect of significant benefit. Forming the right "membership" in an asset pool is akin to forming the "right" portfolios of securities - except in some cases with some additional, practical constraints.

The demand for services or assets from an "asset pool" or portfolio may call for additional constraints, such as geographical, in selecting those eligible to demand from a particular "asset portfolio." For example, the demand for forklift use in Camden New Jersey will not benefit from inclusion of a demand agent in Los Angeles. In contrast, the demand for computational services from an asset portfolio of computational capacity likely will benefit from demand agents scattered about the globe with individual member demand sensitive to local time-zone dependent demands. 
Separate from the above examples; consider "geographic demand" that varies geographically due to seasonal impact. Tillage, nurture, harvests, and process machinery demand varies by geographic location due to the impact of weather and farming seasons - and attendant planting decisions. Some machinery does in fact "move across" geographic zones to meet time and weather-dependent demand. Separate from more optimal use of the units of equipment, asset pools provide the ability to concentrate multiple units on the rapid harvest of crops having harvest value (and risk exposure) sensitive to short time windows. The quality and value of crop - as well as yield and loss - are sensitive in crops such as vegetables for harvest and processing. Similarly, harvesting wheat at the optimal point of time affects moisture content, harvest loss, and the period of risk exposure for wind loss.

Let's now proceed with development of ideas to support application.

- The expected demand and variance in demand is with respect to a period of time (microsecond, second, minute, hour, day, ...). We call this interval expected demand and interval variance. Dividing the summation of individual demands from different users of the service in a time interval by whole capacity during the same time interval yields an interesting interval efficiency utilization measure, especially from a viewpoint of resource efficiency.

- The behavior of interval demand and variance across a time period represents a timeseries. Time-series analysis has special importance in the case of seasonality. Separately, potential shock demands during a period hold attention, e.g., a disaster and the demands for emergency services, blood, etc. The summation of this time-useefficiency measure across a longer time period provides a longer term measure of asset use. Using a year as an interval makes sense given the frequent use of yearly economic returns. Summation of the incremental measures across tangible asset life offers an indication of the efficiency of resource use.

- Each potential user of the service has an expected demand or use against a "pool of services or asset pool" during a time interval. The unit for the interval is time: the length of time chosen for an interval depends on a number of factors. As an example of the variables involved in interval selection, the time unit for the bean harvest example depends on: units available; harvest rate/unit; unacceptable time of day harvest (e.g., no harvest during hottest six hours of day to limit post harvest product damage); average crop acreage at a location in a region; unit relocation time; plant time of that acreage. The collective effects of these factors might argue for six-hour interval blocks. Given interval definition, the interval variance in expected demand for that user is $v r_{\text {dit }}$. Allow us to defer detailed discussion of these factors to a separate paper, "Selection of Demand Interval in Asset Pool Management" which will offer quantification and illustrations employing these notions.

- The capacity of the pool to satisfy the expected demand of those allowed into the pool represents the maximum invested capital possible, but will perhaps not be a desirable outcome. Malfunction probability of each product and the correlation of fault causation across units influence these decisions.

- The pool of resources has invested capital. 
- Value creation and sustainability both benefit from achieving the same expected benefits with less capital employed (and at risk). For value creation, availability can be one of the parameters to measure. Accessibility to one of the products in a pool as well as from malfunction probability of each product influences availability.

- In the normal context of PFT, one characterizes demand from different demand agents within the same time interval.

- One can potentially think in terms of demand cross-time correlation for different time intervals - unlike the application to financial portfolios that generally think of expected returns of each asset tied to the same time period. We will term possible benefits from this scenario as deviant portfolio benefits.

- Seasonal change of the expected demand is different in focus than interval demand. Plans for inventory levels relate to differences in expected seasonal demand. At the same time but with a different focus, one gives attention to analysis of demand behavior during a particular interval, e.g., within a twenty-four hour period. Hence this does not represent traditional time series since the characteristics of the statistical distribution may differ across successive periods.

- Pool managed versus physical dispersal of assets is still another potential harvest from portfolio effects. Units of the assets might be dispersed into sub pools, but the pools collectively managed as one pool. A whole blood supply represents an example. ${ }^{4}$

- Cross-user planning and optimization in the use of asset pools offers potential savings in costs and reduction in collective invested capital.

\subsection{Asset use versus servicing of assets in the pool}

Selling the rights to asset use from the pool offers a different revenue stream from the service of assets in the pool. Asset use demand differs from potential service work to support asset operation. Service work required for assets in the pool under this pooling scheme of business holds interest in research for several reasons. Naturally, the servicing of assets in the pool in terms of preventative, operation, and corrective repair affect the true availability and reliability of pool assets to meet the "portfolio of demand users."

Second, implications exist for the asset pool product/service provider in terms of capital invested in the pool, revenues, and attendant costs. The owner of assets in the pool or a separate party may offer service on assets in the pool, and in a more efficient manner due to purchasing power, efficiency of labor, and other economic factors that stem from economies of scale. However, potential portfolio benefits exist - including a portfolio effect on the potential reduction in investment attendant with the service support function. For example, the portfolio effect will result in a lower inventory of spare parts to support a pool of assets, provided failure of assets in the pool is less than perfectly correlated.

Importantly, service of assets in the pool (separate from demand of asset use and revenue received for providing asset use) entail costs for servicing assets in the pool. Additional revenues associated with the servicing of assets hopefully more than cover these costs and result in net economic income. 


\section{Moving to Applications}

\subsection{Shortfall and stock out/no-fill}

We will use these terms in the common sense of not having the "asset" to use when needed or not having the service availability or product when demanded. PFT offers promise in each of these contexts. ${ }^{5}$

\subsection{Invested capital total (ICT)}

Refer to Figure 2. For simplicity, without a pool of assets assume each company A, B, ... has set invested capital (ICA, ICB, ...) to attain the same probability of shortfall P[SF] in filling demand. For convenience - not necessity - we set the P[SF] at the same level for each company. The separate IC's for each company as well as sum of these amounts (ICT) appear in the top half of Figure XY, for the case when expected demand for asset use has perfect positive correlation across companies: no magic.

The bottom half of the figure represents the instance when demand across companies enjoys $\rho<1$. Then the pool of assets requires less ICT for the same P[SF] since the portfolio effect reduces the variance in net demand.

$$
<<\text { Position of Fig. 2. }>>
$$

Fig. 2. Correlation of demand, total invested capital, and stockout.

In order to construct (Constructing) a simple example to support discussion ${ }^{6}$, let's assume ICT to sustain an expected demand of asset use of $\mathrm{X}$ with $\mathrm{P}[\mathrm{SF}]$ below:

ICT $=100$ units, without the application of PFT methods

$\mathrm{ICT}=\underline{76}$ units, with application of PFT methods

24 units unnecessary capital at risk (UCAR)

With the same level of risk associated with $\mathrm{P}[\mathrm{SF}]$. The lack of perfect correlation of demand result in the benefits of PFT, allowing one to reduce the ICT while keeping the same $\mathrm{P}[\mathrm{SF}]$.

Alternatively we can examine the risk-reducing effects of pooling using a simple example. We can see the effects of portfolio theory by examining the risk/return characteristics of pooling units versus distributing them between two operating divisions $\mathrm{A}$ and $\mathrm{B}$. We combine the risk $(\sigma)$ and average measures by using the Coefficient of Variation, defined as:

$$
C V=\frac{\sigma}{\mu}
$$

which provides a measure of risk per average unit of demand or capital employed. 


\begin{tabular}{lccc} 
Year & Division A units & Division B units & Pooled units \\
\hline 1 & 10 & 8 & 18 \\
2 & 15 & 12 & 27 \\
3 & 7 & 15 & 22 \\
4 & 11 & 13 & 24 \\
& & & \\
Mean & 10.75 & 12 & 22.75 \\
Standard Deviation & 3.304 & 2.944 & 3.775 \\
Coefficient of Variation & 0.307 & 0.245 & 0.166
\end{tabular}

Clearly, both Division A and Division B have variable demand for invested capital from yearto-year. Notice, however, that the risk per unit of invested capital as measured by the Coefficient of Variation is much lower for the overall pooled demand than for either Division A or B by themselves. This illustrates a key characteristic of PFT: Adding "risky" or uncertain assets together results in a portfolio that is actually less risky than either asset alone as long as the two divisions are not perfectly correlated.

\subsection{Implications for Capital and Sustainability}

Eliminating UCAR is important in the context of valuation and sustainability. Furthermore, if we can generate incremental returns (not traceable to a portfolio effect, but to other opportunities), we can gain increments in value. In valuation, we have several core sources of expected benefits, falling into one of these categories.

Invested capital, returns, and risk issues. Reducing the amount of capital and/or the risk exposure of capital used to support a given level of operations are important in the context of common measures of the efficiency of capital use, returns, and value creation. Considering the patience of the reader, we defer details to future papers. However, the potential includes:

- The same expected benefits with the same P[SF], with less invested capital.

- Increased expected benefits from more efficient use of assets, while maintaining the $\mathrm{P}[\mathrm{SF}])^{7}$

- Increase return on capital employed. (Separate from incremental returns that may exist from serving the assets in the pool, and discussed elsewhere in this paper.)

- Reduce capital exposed at risk.

- Less capital required to support growth in demand.

- Reduction of lost capital, this stemming from less capital exposed to various risks such as obsolescence, economic depreciation, and other factors.

\subsection{Sustainability}

Using less capital to achieve the same beneficial effects is a core principle in sustainability. Garnering a portfolio benefit offers the prospect of:

- Reduction in the capital consumed to provide need fulfillment - a critical issue in sustainability for non-renewable resources.

- Greater need fulfillment relative to the use of resources. 
- Favorably altering the Need Fulfillment/Resource Use (NFRU) Ratio, both by changing the numerator and the denominator. In efficient markets, more efficient use of capital reduces the cost of capital in the costs of goods and services - with the attendant reduction in the costs of need fulfillment. This is a numerator effect. Reduction in capital consumed results in a reduction in costs that results in both a denominator and numerator effect.

- In efficient markets, achieving greater efficiency in the use of assets distills a lower cost of financial capital with attendant increase in value.

\subsection{Pool Management Strategy}

Managing a pool of tangible assets to meet user demand involves an array of issues. ${ }^{8} \mathrm{~A}$ brief highlight of some includes:

Critical time obsolescence. Assets that are critical in supply or that have high social or economic costs, and/or that have diminishing value with time offer potential benefits from asset pool management. A whole blood supply pool is a perfect example.

Collars and maximum draw. One can set the minimum and maximum allowed demand fulfillment of an individual company using the pool. The collars and maximum draw can exceed (if portfolio benefit is present) the individual user's ability to meet demand compared to possession of the assets in-house. This yields a benefit to the user by reducing user demand stock-out risk.

Manager penalties. Other variants include, e.g., max variance allowed/tolerated by an individual pool user and, guaranteed availability to a user with a predefined penalty paid by the pool manger if the pool cannot fulfill the demand.

"Overdrafts" and charges. One might set maximum draws allowed in an emergency, with attendant incremental costs to the user that exceeds the collars.

Pool membership. Even though a large number of users may exist for demand of a particular service, one may find it better to form more than one servicing pool. Common sense might dominate over the incremental PF benefits of putting everyone in the same pool. Concerns about having too large a single pool (e.g., thinking in terms of a bank that is too big to fail), geographic issues if service has a transportation and/or time dimension might suggest separate pools. Separate pools could choose to assist another pool while avoiding compulsory assistance.

Cross-seasonal demand. Seasonal demand issues extend beyond the normal seasonal calendar. Significant PF benefits to servicizing likely stem more from within-day variance of demand, with individual user demand tied to the local clock for the "process time."

Time-dependent demand. PFT for securities relates to the behavior of the individual assets with respect to the same period of time, e.g., daily, monthly returns. In our application the relationships are not exactly in concordance with the assumptions of PFT, e.g., expected period returns. Nevertheless, in a practical sense we can benefit from the notions of PFT, admitting these are deviant (but practical) rather than pure portfolio benefits. ${ }^{9}$

The demand for use of an asset/service may vary at the same moment of time, or within a relevant period, e.g., a day. A reservation center is an example, with demand varying greatly 
at specific times in an interval, as well as within a calendar day - with same time demand (ST) as well as within-day demand (WD) jointly influencing demand on the pool. One might create subsets of demand customers that have access to the asset pool only during specified periods, referring to these groups as segmented demanders. Creating a particular array of segmented demands having time specific windows of claim against a resource pool offers additional possibilities.

Cross-pool management. For certain types of assets or claims on service (e.g., information processing), managers of different pools might gain additional benefits by limited coinsurance of demand across different pools of assets.

Aberrant or derivative portfolio benefits. This notion stems from the fundamental difference in the application of portfolio theory to non-financial assets and services, rather than financial assets. Efficiency in the access and use of assets to fulfill need fulfillment might (likely) changes actual demand functions as well as cost structures, ease of entry and competition, and other factors.

\subsection{Ideas for Research}

A sample of potential avenues for additional research includes:

- The use of PFT in the selection of demand agents that can claim use of an asset pool. This is separate from the portfolio effect in the pool of assets.

- The optimal physical dispersion of physical assets to meet demand.

- PFT and the design of products and critical faults.

- Mass Customization (MC) (Pine 1993) and its influence on economies and the environment offers an array of interesting future works (Sakao et al. 2010). A company employing MC keeps different modules "in inventory" to use in response to demand of a customized product. In principle, the level of need fulfillment is higher with MC than mass production of standardized products. On the other hand, the quantitative influence of MC on the resource employed/used is to be investigated.

- The Need Fulfillment/Resource Use ratio reflects the success at fulfilling human needs relative to the resources employed and/or depleted in the process. ${ }^{10}$ Providing a desired level of light employing/depleting the lowest resource use represents an example. Tailoring a product or service to better match individual desires and preferences in need fulfillment relative to resource use are another example - and an example of potential benefits of Mass Customization -- as a measure of resource use efficiency and sustainability.

- Servicizing and Use versus Ownership: Implications for Marketing examines derivative marketing implications that result from the user of the product/service being different from the owner/provider. For example, in the case of car share, decisions related to fueling, servicing options, tire replacement and similar purchase decisions do not rest on user decisions.

\section{Conclusions}

The concepts and implications of portfolio theory (PFT) offer opportunities outside of the finance field. In particular, the "pooling" of assets/services to meet uncertain demands from different users of an asset/service pool may yield benefit from diversification effects. Those benefits include a reduction in capital employed to fulfill customer needs, more favorable costs structures, a change in total net demand, and derivative benefits to sustainability. 
The paper has raised issues, offered perspectives, and suggested avenues for additional research. Special application of portfolio theory outside the realm of pure finance will yield benefits that affect the creation of value in an economy. In particular, this paper provided insights and lent support to how portfolio principles applied outside the arena of investments can affect:

- Invested capital required to support a business process.

- The magnitude and impact of idle capital.

- The opportunity to reduce idle capital with attendant benefits.

- The potential loss of capital, of special concern if capital is perishable and/or subject to obsolescence.

- Risk, returns, and resultant value creation.

- Special benefits that may stem from application in the "service inventory" as well as for tangible units of input, process, or product.

- The favorable impact of portfolio theory and wise choice on sustainability.

- Increased returns on financial and tangible capital.

- Improvement in the Need Fulfillment/Resource Use Ratio, in support of sustainability.

- The positive impact on the efficiency of human capital.

To the extent we have stimulated thoughts and provoked debate and future exploration, we will have achieved a key objective. The promise and expectation of benefiting from appreciating and harvesting from multiple disciplines attracts us. Different disciplines have their "own crayons." We suspect that the beauty of art stems from all the brush strokes collectively offering insights and perspectives. This paper illustrates how portfolio principles applied outside the arena of investments can yield benefits, including the fulfillment of needs with the least resource used - a core principle in sustainability. This special application of portfolio theory outside the realm of finance can yield benefits that positively affect the creation of value and resource use in an economy at large. 


\section{Appendix}

Computation of Portfolio Variance for Portfolios with More Than Two Assets

The portfolio example in the paper used two assets for simplicity. Using a matrix, it is not difficult to calculate the portfolio variance for more assets. The matrix below illustrates a covariance matrix for the returns of three assets, $\mathrm{X}, \mathrm{Y}$, and $\mathrm{Z}$.

\begin{tabular}{llll}
\multicolumn{5}{c}{ Bordered Covariance Matrix } \\
Portfolio Weights & $\mathrm{w}_{\mathrm{x}}$ & $\mathrm{w}_{\mathrm{y}}$ & $\mathrm{w}_{\mathrm{z}}$ \\
\cline { 2 - 3 } & $\operatorname{Cov}\left(\mathrm{r}_{\mathrm{x}}, \mathrm{r}_{\mathrm{x}}\right)$ & $\operatorname{Cov}\left(\mathrm{r}_{\mathrm{x}}, \mathrm{r}_{\mathrm{y}}\right)$ & $\operatorname{Cov}\left(\mathrm{r}_{\mathrm{x}}, \mathrm{r}_{\mathrm{z}}\right)$ \\
$\mathrm{w}_{\mathrm{y}}$ & $\operatorname{Cov}\left(\mathrm{r}_{\mathrm{y}}, \mathrm{r}_{\mathrm{x}}\right)$ & $\operatorname{Cov}\left(\mathrm{r}_{\mathrm{y}}, \mathrm{r}_{\mathrm{y}}\right)$ & $\operatorname{Cov}\left(\mathrm{r}_{\mathrm{y}}, \mathrm{r}_{\mathrm{z}}\right)$ \\
$\mathrm{w}_{\mathrm{z}}$ & $\operatorname{Cov}\left(\mathrm{r}_{\mathrm{z}}, \mathrm{r}_{\mathrm{x}}\right)$ & $\operatorname{Cov}\left(\mathrm{r}_{\mathrm{z}}, \mathrm{r}_{\mathrm{y}}\right)$ & $\operatorname{Cov}\left(\mathrm{r}_{\mathrm{z}}, \mathrm{r}_{\mathrm{z}}\right)$
\end{tabular}

Note that the diagonal of the matrix represents the covariance of an asset's returns with itself, i.e. the variance of asset returns.

To illustrate how to use the matrix to calculate the portfolio variance we can multiply through by the weights on the matrix border.

Border-Multiplied Covariance Matrix

\begin{tabular}{llll} 
Portfolio Weights & $\mathrm{w}_{\mathrm{x}}$ & $\mathrm{w}_{\mathrm{y}}$ & $\mathrm{w}_{\mathrm{z}}$ \\
\hline $\mathrm{w}_{\mathrm{x}}$ & $\mathrm{w}_{\mathrm{x}} \mathrm{w}_{\mathrm{x}} \operatorname{Cov}\left(\mathrm{r}_{\mathrm{x}}, \mathrm{r}_{\mathrm{x}}\right)$ & $\mathrm{w}_{\mathrm{x}} \mathrm{w}_{\mathrm{y}} \operatorname{Cov}\left(\mathrm{r}_{\mathrm{x}}, \mathrm{r}_{\mathrm{y}}\right)$ & $\mathrm{w}_{\mathrm{x}} \mathrm{w}_{\mathrm{z}} \operatorname{Cov}\left(\mathrm{r}_{\mathrm{x}}, \mathrm{r}_{\mathrm{z}}\right)$ \\
$\mathrm{w}_{\mathrm{y}}$ & $\mathrm{w}_{\mathrm{y}} \mathrm{w}_{\mathrm{x}} \operatorname{Cov}\left(\mathrm{r}_{\mathrm{y}}, \mathrm{r}_{\mathrm{x}}\right)$ & $\mathrm{w}_{\mathrm{y}} \mathrm{w}_{\mathrm{y}} \operatorname{Cov}\left(\mathrm{r}_{\mathrm{y}}, \mathrm{r}_{\mathrm{y}}\right)$ & $\mathrm{w}_{\mathrm{y}} \mathrm{w}_{\mathrm{z}} \operatorname{Cov}\left(\mathrm{r}_{\mathrm{y}}, \mathrm{r}_{\mathrm{z}}\right)$ \\
$\mathrm{w}_{\mathrm{z}}$ & $\mathrm{w}_{\mathrm{z}} \mathrm{w}_{\mathrm{x}} \operatorname{Cov}\left(\mathrm{r}_{\mathrm{z}}, \mathrm{r}_{\mathrm{x}}\right)$ & $\mathrm{w}_{\mathrm{z}} \mathrm{w}_{\mathrm{y}} \operatorname{Cov}\left(\mathrm{r}_{\mathrm{z}}, \mathrm{r}_{\mathrm{y}}\right)$ & $\mathrm{w}_{\mathrm{z}} \mathrm{w}_{\mathrm{z}} \operatorname{Cov}\left(\mathrm{r}_{\mathrm{z}}, \mathrm{r}_{\mathrm{z}}\right)$ \\
\hline $\mathrm{w}_{\mathrm{x}}+\mathrm{w}_{\mathrm{y}}+\mathrm{w}_{\mathrm{z}}=1$ & & &
\end{tabular}

The portfolio variance results from summing the covariances:

$\sigma_{p}^{2}=w_{x}^{2} \sigma_{x}^{2}+w_{y}^{2} \sigma_{y}^{2}+w_{z}^{2} \sigma_{z}^{2}+2 w_{x} w_{y} \operatorname{Cov}\left(r_{x}, r_{y}\right)+2 w_{x} w_{z} \operatorname{Cov}\left(r_{x}, r_{z}\right)+2 w_{y} w_{z} \operatorname{Cov}\left(r_{y}, r_{z}\right)$

This technique for calculating portfolio variance is easily adapted for any number of assets and is ideally suited for spreadsheet use. 


\section{References}

Alonso-Rasgado, T., Thompson, G., and Elfstrom, B., 2004. The design of functional (total care) products. Journal of Engineering Design, 15 (6), 515-540.

Bai, C., and Sarkis, J., 2010. Integrating sustainability into supplier selection with grey system and rough set methodologies. International Journal of Production Economics, 124, 252-264.

Bullinger, H., Fahnrich, K., and Meiren, T., 2003. Service engineering - methodical development of new service products. International Journal of Production Economics, $11,275-287$.

DeSimone, L., and Popoff, F., 1997. Eco-efficiency - The Business Link to Sustainable Development -, (MIT Press: Cambridge, MA).

Edvardsson, B., 1997. Quality in new service development: Key concepts and a frame of reference. International Journal of Production Economics, 52 (1-2), 31-46.

Elton, E.J., and Gruber, M.J., 1977. Risk Reduction and Portfolio Size: An Analytic Solution. Journal of Business, 50, 415-437.

Elton, E.J., and Gruber, M.J., 1997. Modern Portfolio Theory, 1950 to date. Journal of Banking and Finance, 21, 1743-1759.

Evans, J., and Archer, S., 1968. Diversification and the Reduction of Dispersion - an Empirical Analysis. Journal of Finance, 23, 761-767.

Fama, E.F., and French, K., 1992. The Cross-Section of Expected Stock Returns. Journal of Finance, 47 (2), 427-466.

Goetzmann, W., 2010. An Introduction to Investment Theory. In. Yale School of Management, http://viking.som.yale.edu/will/finman540/classnotes/notes.html.

Huppes, G., and Ishikawa, M., 2005. Special issue on eco-efficiency. Journal of Industrial Ecology, 9 (4), 2-240.

Johnson, M.D., Herrmann, A., and Huber, F., 1998. Growth through Product-Sharing Services. Journal of Service Research, 1 (2), 167-177.

Krysiak, F.C., 2009. Sustainability and its relation to efficiency under uncertainty. Economic Theory, 41, 297-315.

Lindahl, M., Rönnbäck, A.Ö., and Sakao, T., 2009. Business Implications of Integrated Product Service Offerings and Resulting Potential Engineering Issues. In 17th International Conference on Engineering Design -ICED09-. Stanford, USA.

Lintner, J., 1965. The Valuation of Risk Assets and the Selection of Risky Investments in Stock Portfolios and Capital Budgets. Review of Economics and Statistics, 47 (1), 13 37.

Markowitz, H.M., 1952. Portfolio Selection. Journal of Finance, 7 (1), 77-91.

Markowitz, H.M., 1959. Portfolio Selection: Efficient Diversification of Investments, (Wiley: New York).

Mossin, J., 1966. Equilibrium in a Capital Asset Market. Econometrica, 34 (4), 768-783.

OECD, 2001. Extended Producer Responsibility: A Guidance Manual for Governments, (OECD: Paris). 
Pine, J., 1993. Mass Customization: the New Frontier in Business Competition, (Harvard Business School Press: Boston, MA).

Prettenthaler, F.E., and Steininger, K.W., 1999. From ownership to service use lifestyle: the potential of car sharing. Ecological Economics, 28, 443-453.

Ron, A.J.d., 1998. Sustainable production: The ultimate result of a continuous improvement. International Journal of Production Economics, 56-57, 99-110.

Sakao, T., and Fargnoli, M., 2010. Customization in Ecodesign: A Demand-side Approach Bringing New Opportunities? The Journal of Industrial Ecology, 14 (4), 529 - 532.

Sakao, T., Lindahl, M., and Rönnbäck, A.Ö., 2009a. Environmentally-conscious design methods for manufacturing firms with servicification. International Journal of Automation Technology, 3 (1), 26-32.

Sakao, T., and Shimomura, Y., 2007. Service Engineering: A Novel Engineering Discipline for Producers to Increase Value Combining Service and Product. Journal of Cleaner Production, 15 (6), 590-604.

Sakao, T., Shimomura, Y., Sundin, E., and Comstock, M., 2009b. Modeling Design Objects in CAD System for Service/Product Engineering. Computer-Aided Design, 41 (3), 197-213.

Sharpe, W.F., 1964. Capital Asset Prices: A Theory of Market Equilibrium Under Conditions of Risk. Journal of Finance, 19 (3), 425-442.

Statman, M., 1987. How Many Stocks Make a Diversified Portfolio? Journal of Financial and Quantitative Analysis, 22, 353-364.

Sundin, E., Lindahl, M., and Larsson, H., 2010. Environmental and Economic Benefits of Industrial Product/Service Systems. In CIRP IPS2 Conference, (Sakao, T.-., et al., Eds.), pp. 91-98. Linköping.

Tukker, A., 2004. Eight Types of Product-Service System: Eight Ways to Sustainability? Experiences from Suspronet. Business Strategy and the Environment, 13, 246 - 260.

Tukker, A., and Tischner, U., 2006a. New Business for Old Europe, (Greenleaf Publishing: Sheffield).

Tukker, A., and Tischner, U., 2006b. Product-services as a research field: past, present and future. Reflections from a decade of research. Journal of Cleaner Production, 14 (17), 1552-1556.

UNEP, 1997. ECODESIGN: a promising approach to sustainable production and consumption, (United Nations Publication: Paris).

Weizäcker, E.v., Lovins, A., and Lovins, L.H., 1998. Factor Four - Doubling Wealth, Halving Resource Use, (Earthscan Publications Limited: London).

White, A.L., Stoughton, M., and Feng, L., 1999. Servicizing: The Quiet Transition to Extended Product Responsibility, Tellus Institute.

Yamaguchi, J., 1999. Honda begins field operation of Intelligent Community Vehicle System. Automotive Engineering International 107 (2), 28-33. 


\section{Vitae}

Dr. Steve Byers is a professor in the College of Business at Idaho State University. He received his Ph.D. (Finance) from Texas A\&M University. He also holds a degree in mathematics and an MBA in finance, both from Indiana University. He teaches graduate and undergraduate courses in investments and corporate finance. His research has been published in academic journals such as Journal of Money, Credit, and Banking, Journal of Corporate Finance, European Business Review, and Applied Financial Economics. Steve has corporate finance experience with NCR Corporation and Bristol-Myers. He also served in the U.S. Navy as a nuclear submarine officer.

John C. Groth - Professor of Finance, Mays School, Texas A\&M University. PhD, Krannert School, an M.S.I.A, and a degree in physics. Awards: Distinguished Fulbright - 2002, Mays Faculty Fellow for Teaching Innovation; University Faculty Distinguished Achievement Award in Teaching, and many others. Heck and Cooley cite him as a "Most Frequent Appearing Authors in 26 Core Finance Journals." Interdisciplinary papers appear in Creativity \& Innovation Management, Journal of Accountancy, Journal of Consumer Marketing, Journal of Product \& Brand Management, and other journals. A retired naval officer, O-6, he had three commands and served as a chief engineer.

Tomohiko Sakao has been professor at the Division of Environmental Technology and Management, the Department of Management and Engineering, Linköping University, Sweden since 2007. He has been a visiting researcher at the University of Tokyo and at Technical University of Berlin since 2002 and 2009, respectively. His research interests include Ecodesign and Integrated Product Service Engineering. He served as a lecturer of a dissemination program of environmental business by METI (Ministry of Economy, Trade, and Industry), Japan in 2004/5. He was an awardee of research fellowship by the Humboldt Foundation at Darmstadt University of Technology, Germany from 2005 to 2007.

\section{Figure Captions}

Fig. 1. Diversification of unsystematic risk with increase in number, $n$.

Fig. 2. Correlation of demand, total invested capital, and stockout. 


\section{Figures}

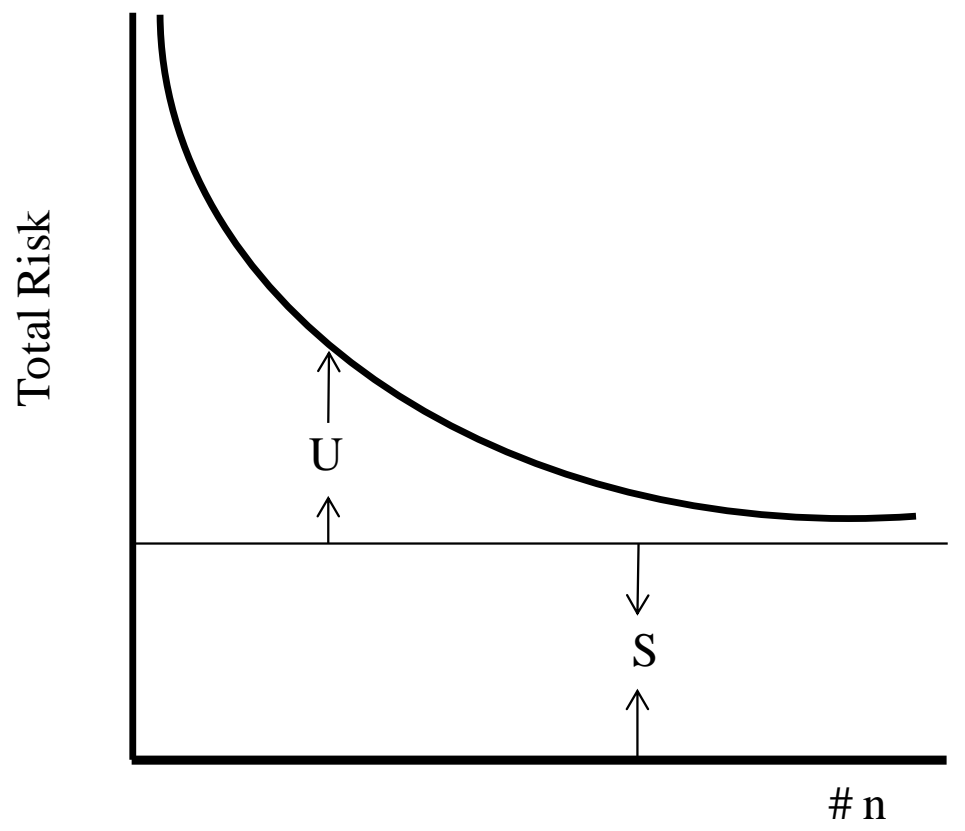

U: unsystematic risk S: systematic risk

$\mathrm{n}$ : number securities (or other stochastic variables)

Fig. 1. Diversification of unsystematic risk with increase in number, $n$.
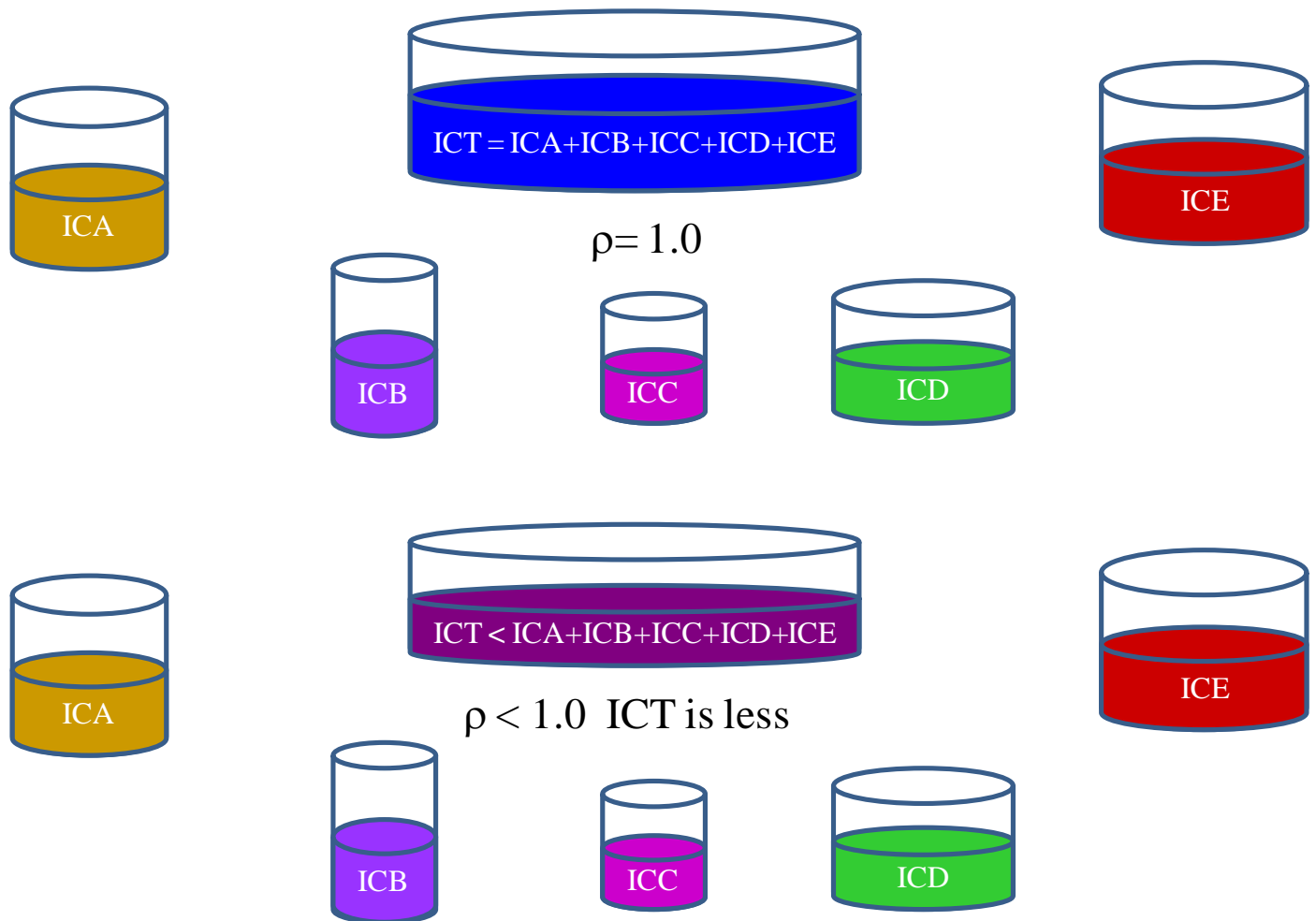

For a given probability of no fill of demand: Total invested capital if demands A, B, C, D, E $\rho=1.0$ \& if $\rho<1.0$. $\rho$ is correlation of expected demand. IC $=$ invested capital and ICT is total invested capital.

Fig. 2. Correlation of demand, total invested capital, and stockout. 
${ }^{1}$ Careful development of human capital offers the potential of increasing, rather than merely sustaining, human capital. A separate paper will address core issues in this area.

${ }^{2}$ Portfolio theory has application in quality control, redundancy, design, critical fault, medical treatment, weapons deployment, trials and analysis, automated analysis and other areas. Some of these topics are the subject of research by one or more of the authors.

${ }^{3}$ http://www.hondadiracc.com accessed on March 7th, 2008.

${ }^{4}$ Groth and Flores gave attention to this. See Groth and Flores (1989).

${ }^{5}$ Another paper will give attention to special applications of PFT in quality control as well as in safety, product and system design, redundancy, and related issues.

${ }^{6}$ Not a calculation using actual correlations etc.

${ }^{7}$ This represents a potential benefit not thought available in the context of financial securities. The expected return of a portfolio of securities is simply a weighted average.

8 "Pooled Asset Management: Implications of Demand and Asset Characteristics" hold interest for a future paper.

${ }^{9}$ We recognize that one can shorten the period for examination of demand against the asset pool, in extreme to the limits. In a practical sense, the shortest unit of time is the minimum time usage a customer of the pool can use the asset to achieve benefit. We defer the mathematics of this to another occasion.

${ }^{10}$ Efforts to fulfill needs may employ (with recoverability) and/or deplete resources in the process. For brevity, we will use "resource use" meaning both use and or depletion. 